\title{
ANÁLISE DO COMPORTAMENTO MORFOLÓGICO E TÉRMICO DE MINERIAS DO MUNICIPIO DE CAMPOS DOS GOYTACAZES *
}

Afonso Garcez de Azevedo ${ }^{1}$

Sérgio Neves Monteiro ${ }^{2}$

Jheison Lopes dos Santos ${ }^{3}$

\section{Resumo}

As indústrias cerâmicas do Parque Industrial do Município de Campos dos Goytacazes-RJ utilizam como matéria-prima a argila oriunda das jazidas presentes na planície de inundação do Rio Paraíba do Sul. Os artefatos produzidos por essas indústrias, que são na sua maioria tijolos e telhas, apresentam propriedades provenientes das transformações que ocorrem na constituição mineralógica da matéria-prima após queima, bem como do processo de fabricação empregado. Com o intuito de melhor entender o processo de fabricação destes artefatos e como suas propriedades se desenvolvem, este trabalho pretende caracterizar e identificar os minerais constituintes de uma camada argilosa do Município de Campos dos Goytacazes-RJ, usando, para isso, técnica de Difração de Raios-X, e analisar as transformações térmicas ocorridas através de ADT/ATG/TG e microscopia óptica.

Palavras-chave: Argila; Minerais; Transformações térmicas.

\section{ANALYSIS OF MORPHOLOGICAL AND THERMAL BEHAVIOR OF MINERALS OF THE MUNICIPALITY OF CAMPOS DOS GOYTACAZES}

\section{Abstract}

The ceramic industries of the Industrial Park of Campos dos Goytacazes-RJ use as raw material the clay originated from the deposits found in the floodplain of the Paraíba do Sul River. The artifacts produced by these industries, which are mostly bricks and tiles, present properties derived from the transformations that occur in the mineralogical constitution of the raw material after burning, as well as the manufacturing process employed. In order to better understand the manufacturing process of these artifacts and how their properties develop, this work intends to characterize and identify the minerals constituent of a clayey layer of the Municipality of Campos dos Goytacazes-RJ, using, for this, X-ray diffraction technique, and analyze the thermal transformations occurring through DSC/DTG/TGA and optical microscopy.

Keywords: Clay; Minerals; Thermal transformations

1 Mestre em Engenharia Civil, Doutorando em Engenharia Civil, Laboratório de Engenharia Civil, Universidade Estadual do Norte Fluminense, Campos dos Goytacazes, RJ, Brasil.

2 Ph.D. em Engenharia de Materiais, Professor, Seção de Engenharia Mecânica e de Materiais, Instituto Militar de Engenharia, Rio de Janeiro, RJ, Brasi.

3 Doutor em Ciência dos Materiais, Pós-Doutorando, Seção de Engenharia Mecânica e de Materiais, Instituto Militar de Engenharia, Rio de Janeiro, RJ, Brasil. 


\section{INTRODUÇÃO}

A indústria cerâmica do Município de Campos dos Goytacazes ocupa um lugar de destaque no Estado de Rio de Janeiro, representando grande parte da produção total do estado, a qual é de mais de 150 milhões de peças por mês.

Visando o conhecimento das transformações térmicas que ocorrem nos minerais e argilominerais presentes nas jazidas de argila do município de Campos, este trabalho pretende contribuir para a melhoria da qualidade dos artefatos produzidos nas indústrias cerâmicas, visto as transformações térmicas serem as principais responsáveis pelas alterações que ocorrem nas propriedades cerâmicas.

Muitos estudos têm sido desenvolvidos em escala global, sobre a composição, estrutura e as propriedades fundamentais dos constituintes das argilas, bem como sua forma de ocorrência e a gênese dos seus vários tipos e a relação dos argilominerais presentes com suas propriedades tecnológicas [1].

Alguns fatores como temperatura, tempo e pressão são fundamentais nas transformações dos minerais, pois as características que os diferenciam, se alteram sob estas condições. No processo de fabricação das cerâmicas, os minerais são novamente expostos a algumas destas condições, o que acarreta transformações nas suas estruturas que influenciam diretamente na qualidade dos mesmos.

Os materiais argilosos sob ação de calor sofrem dilatações e retrações em função da temperatura. $O$ registro dessas mudanças de dimensões resultam em curvas típicas que podem ser modificadas dependendo da composição da argila quer no que se refere aos diversos argilominerais, quer pela presença e quantidade de minerais não plásticos como quartzo, feldspato, calcita [2].

A observação conjunta das micrografias e difratogramas de raios-x (DRX) mostra as alterações dos minerais como feldspato, ilita, caulinita, quartzo, contribuindo para formação da fase vítrea. Na temperatura de $1000^{\circ} \mathrm{C}$, ocorre a nucleação da mulita, de modo que, através de observação em corpos-de-prova, pode-se determinar os fatores mais influentes na formulação, ou seja, qualidade de fundentes, como feldspato e calcita [3].

As Análises Térmicas Diferencial e Termogravimétrica permitem determinar os fenômenos ocorridos durante 0 aquecimento uniforme das matérias-primas, envolvendo liberação ou absorção de energia nas amostras. Tais técnicas são importantes para verificar o comportamento térmico das argilas e confirmar a presença de argilominerais identificados na Difração de Raios- $X$, e também os amorfos não detectáveis em DRX [4].

\section{MATERIAIS E MÉTODOS}

A amostra analisada foi coletada no Parque Industrial Cerâmico do Município de Campos dos Goytacazes, Norte do Estado do Rio de Janeiro, e foi caracterizada conforme os procedimentos descritos a seguir.

\subsection{Caracterização Granulométrica do solo}

Para caracterização das amostras argilosas, foram realizados no Laboratório de Solos do LECIV/UENF, ensaios de granulometria por peneiramento e sedimentação por via úmida, segundo a NBR 7181:1984 [5], para a determinação das frações granulométricas que a compõem. 


\subsection{Separação das frações argila e silte}

A separação granulométrica das frações argila e silte (MIT), foram feitas através do ensaio de peneiramento e sedimentação. Primeiramente foi separada a fração areia por peneiramento na malha de abertura $0,06 \mathrm{~mm}$. A seguir, a amostra foi misturada com solução defloculante de hexametafosfato de sódio e depois de 24 horas foi agitada em dispersor elétrico por 10 minutos. Seguindo a Lei de Stokes quanto ao tempo de sedimentação, separou-se a fração argila da fração silte por pipetagem.

\subsection{Preparação dos Corpos-de-prova}

Os corpos-de-prova foram confeccionados por meio de prensagem, onde 5 gramas de cada amostra, recebeu uma pressão de $20 \mathrm{MPa}$ toneladas, obtendo-se, desta forma, pastilhas com $3 \mathrm{~cm}$ de diâmetro e 0,3 cm.

\subsection{Difração de Raios-X}

Este método foi utilizado para identificação dos argilominerais e minerais presentes no solo mediante a análise dos espectros de raios- $X$ e identificação de suas fases.

\subsection{Análises Térmica Diferencial e Termogravimétrica}

Estas técnicas foram utilizadas para identificar os minerais presentes, através de seu comportamento térmico indicado pelas curvas destes ensaios.

\subsection{Queima em forno Mufla}

Os corpos-de-prova foram submetidos a queima nas seguintes temperaturas: $300^{\circ} \mathrm{C}$, $500^{\circ} \mathrm{C}, 600^{\circ} \mathrm{C}, 900^{\circ} \mathrm{C}$ e $1000^{\circ} \mathrm{C}$ com patamar de queima de 1 hora (patamar utilizado como início de uma série para futuros trabalhos.

\subsection{Microscopia Óptica}

Os corpos-de-prova queimados foram analisados e fotografados no Microscópio Neophot com aumento de 320X/Campo escuro, objetivando-se a identificação morfológica de superfície.

\section{RESULTADOS E DISCUSSÃO}

\subsection{Caracterização Granulométrica da Amostra}

Para caracterização das amostras foram realizados, no Laboratório de Solos do LECIV/UENF, ensaios de granulometria por peneiramento e sedimentação. Os ensaios de distribuição granulométrica realizados determinam as frações granulométricas via úmido por peneiramento e sedimentação segundo a NBR 7181 [5]. O resultado está indicado na Figura 1. 


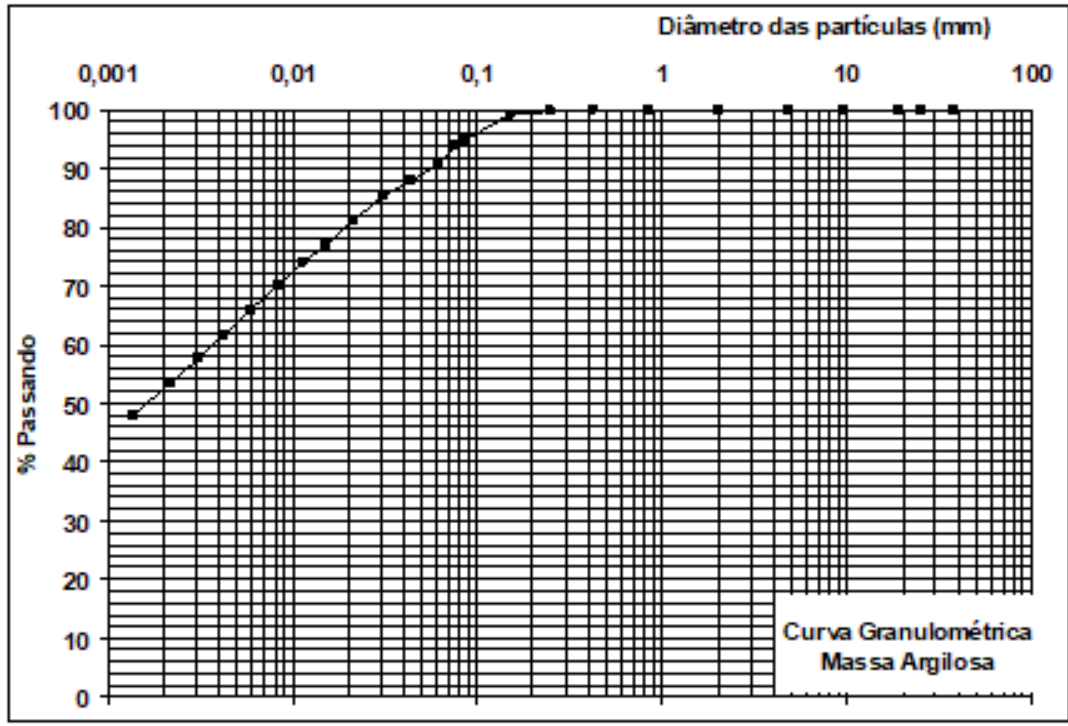

Figura 1. Curva granulométrica da massa argilosa utilizada.

Verifica-se na Figura 1 que as composições granulométricas são subdivididas da seguinte maneira: $52 \%$ de fração argila, $34 \%$ de fração silte e uma pequena fração de areia fina de aproximadamente $14 \%$ (transição do método de peneiramento para o método de sedimentação), sendo por isso, um solo com predominância de partículas muito finas.

\subsection{Difração de Raios-X}

Este método foi utilizado para identificação dos argilominerais e minerais presentes na amostra mediante a análise dos espectros de raios- $x$, feita com base nas reflexões interplanares basais. A seguir, são mostrados nas Figuras 2 e 3 os espectros de raios- $x$ obtidos.

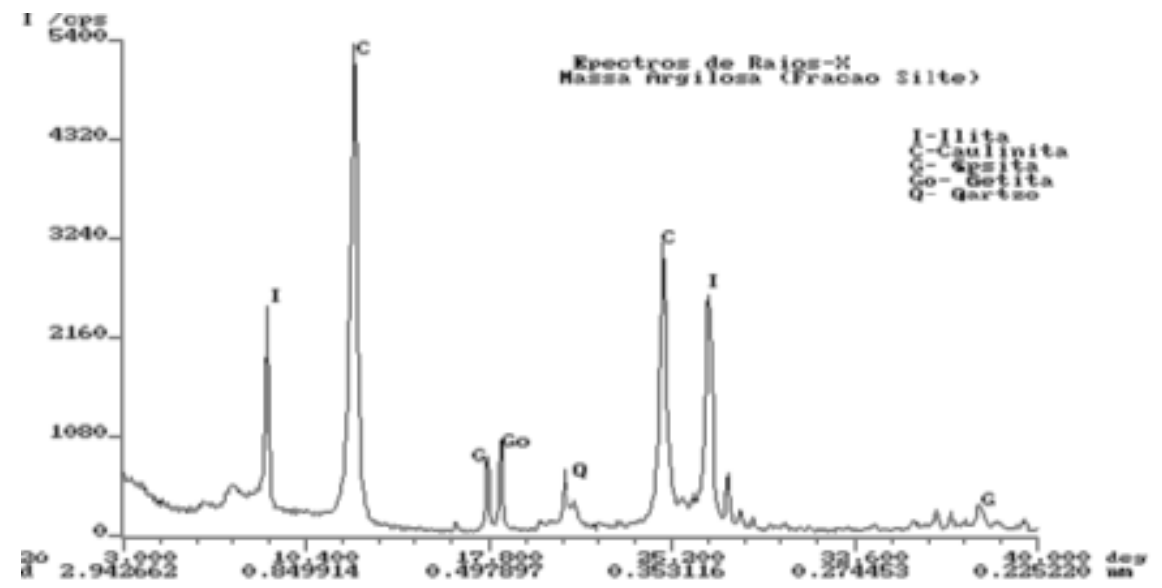

Figura 2. Espectro de Raios-X da fração silte. 


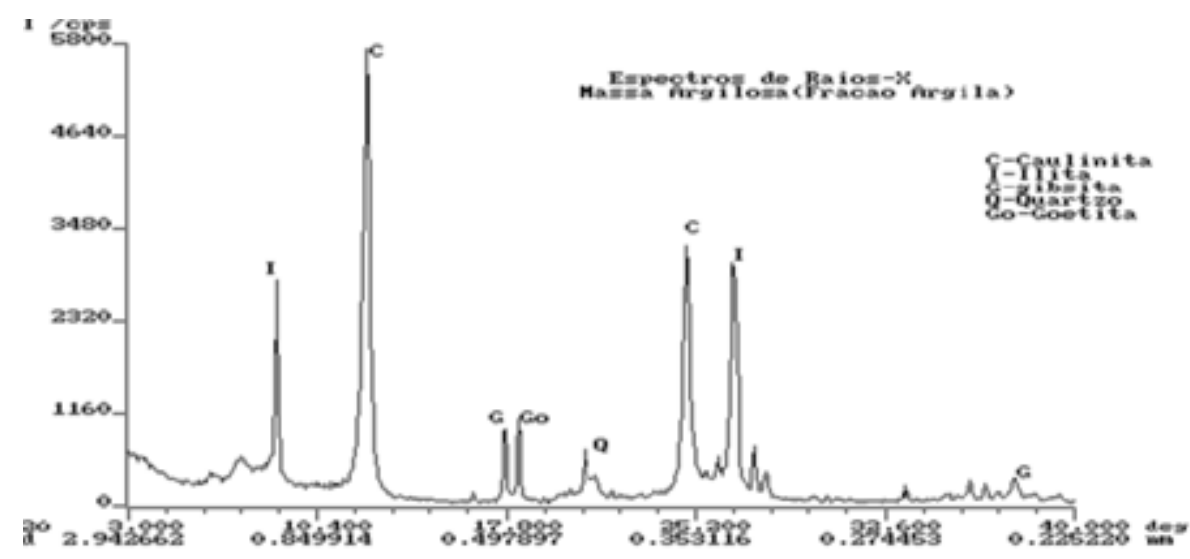

Figura 3. Espectros de raios- $X$ da fração argila.

Observa-se nos espectros de raios-x da massa argilosa, que os picos mais intensos identificaram os argilominerais: caulinita e ilita. Os picos mais discretos identificaram os minerais como quartzo, goetita e gibsita. Podemos observar que tanto na fração argila como na fração silte foram identificados os mesmos minerais, havendo grande semelhança nos espectros.

\subsection{Análises Térmica Diferencial e Termogravimétrica}

Mostra-se nas Figuras 4(a) e 4(b) as curvas das análises térmicas diferenciais realizadas na argila. Analisando a curva de ATD da Figura 4(a), verifica-se que a fração argila apresenta: pico endotérmico de média intensidade a $261,42^{\circ} \mathrm{C}$, devido à reação de desidroxilação dos hidróxidos de alumínio e ferro podendo ser em virtude da presença de gibsita e goetita; pico endotérmico de média intensidade a $487,66^{\circ} \mathrm{C}$ devido a reação de perda de hidroxilas da caulinita dando origem à fase amorfa da caulinita, denominada metacaulinita. Observando as curvas de ATG da Figura 4(b), ocorreu a $247,12^{\circ} \mathrm{C}$ uma perda de massa correspondente a desidroxilação de hidróxidos de alumínio e ferro (devido a gibsita e goetita) uma perda de massa a $442,47^{\circ} \mathrm{C}$ correspondente à perda de hidroxilas da caulinita transformando-se em metacaulinita.

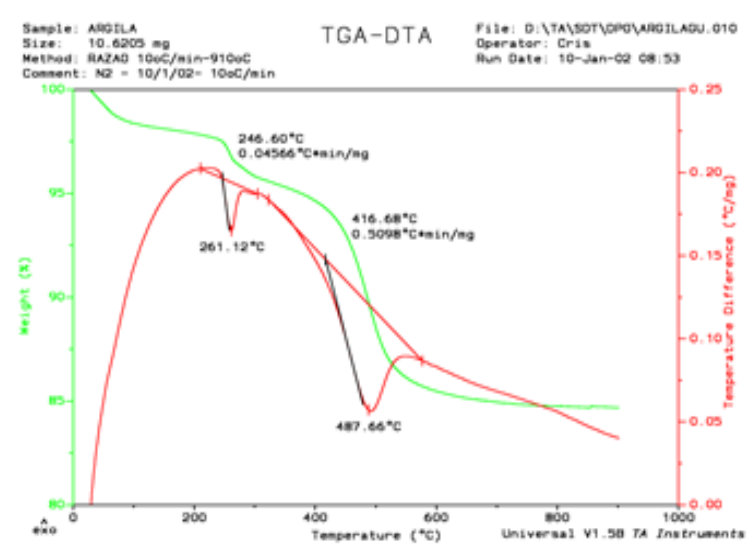

(a)

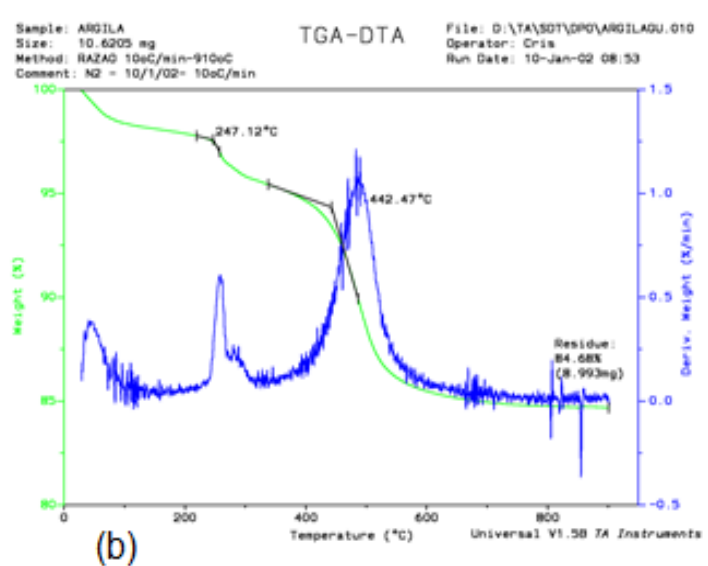

(b)

Figura 4. Curvas de (a) ATD e (b) ATG da fração argila.

As análises térmicas para fração silte são mostradas nas Figuras $5(a)$ e $5(b)$. Verifica-se na curva de ATD da Figura 5(a), que a fração silte apresenta: pico 
endotérmico de pequena intensidade a $267,43^{\circ} \mathrm{C}$, por causa da reação de desidroxilação dos hidróxidos de alumínio e ferro sendo devido provavelmente à presença de gibsita e goetita; ocorreu um pico endotérmico de média intensidade a $489,89^{\circ} \mathrm{C}$ devido a reação de perda de hidroxilas da caulinita dando origem à fase amorfa da caulinita, denominada metacaulinita. Na Figura 5(b), houve uma pequena perda de massa a $243,21^{\circ} \mathrm{C}$ correspondente a desidroxilação de hidróxidos de alumínio e ferro (podendo ser a gibsita e goetita). Houve uma perda de massa a $449,46^{\circ} \mathrm{C}$, correspondente à perda de hidroxilas da caulinita transformando-se em metacaulinita.

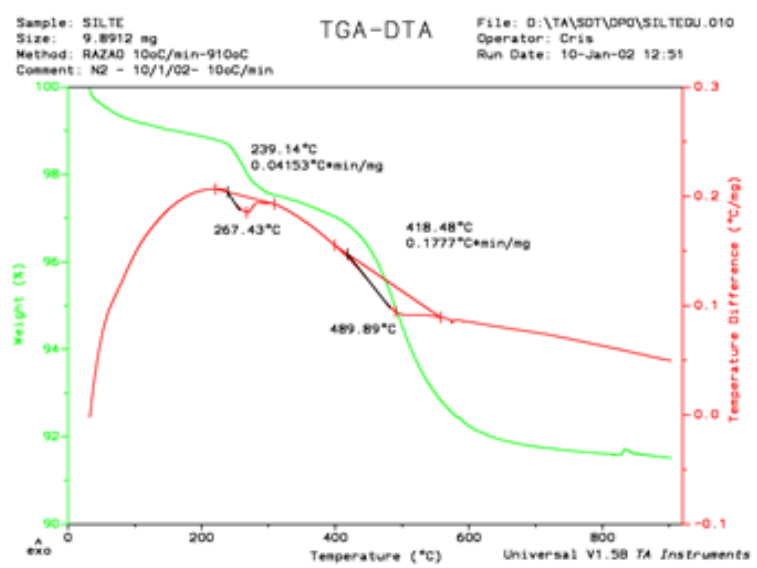

(a)

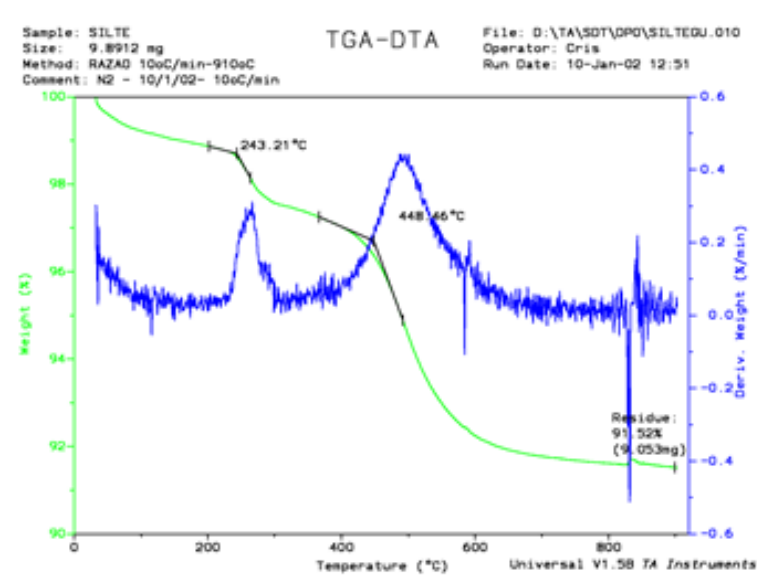

(b)

Figura 5. Curvas de (a) ATD e (b) ATG da fração silte.

\subsection{Microscopia óptica}

Os corpos-de-prova crus e queimados foram analisados e fotografados no Microscópio Neophot com aumento de 320X/Campo escuro. Observa-se na Figura 6(a) que a fração argila sem queimar apresenta coloração amarelada e com aparecimento de pequena quantidade de poros. Na Figura 6(b), à temperatura 300 ${ }^{\circ} \mathrm{C}$, a coloração se torna um pouco avermelhada em função do início da oxidação do ferro, começando à aproximação dos grãos da massa cerâmica.
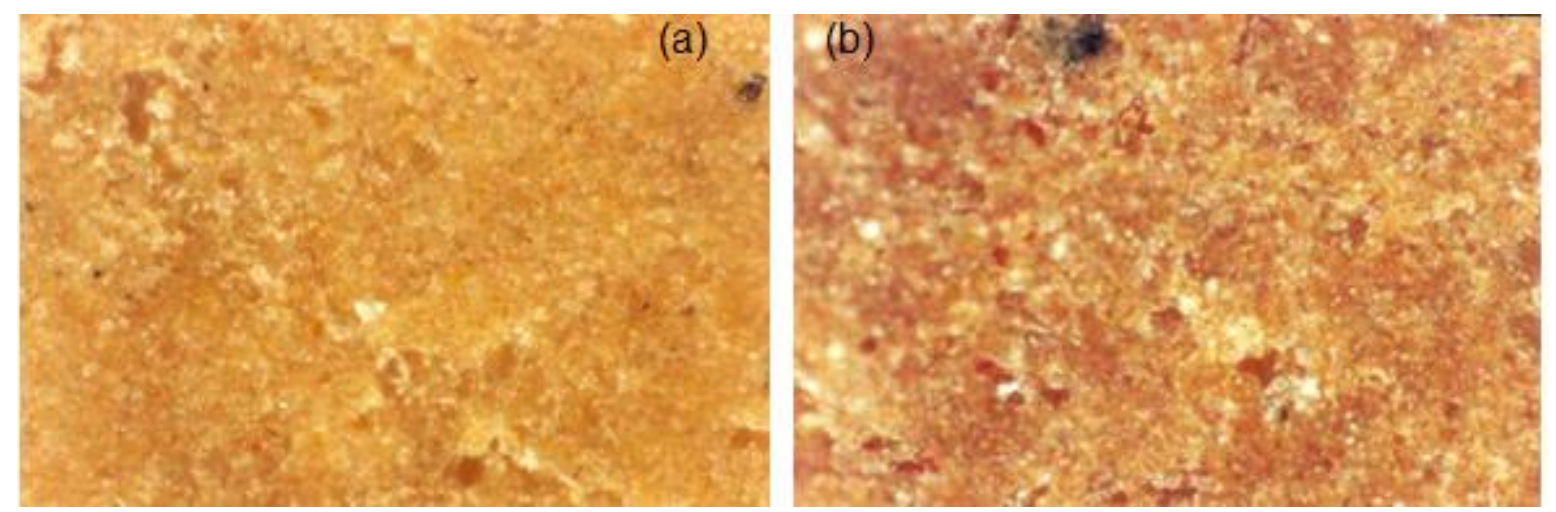

Figura 6. Fração argila (a) não queimada e (b) queimada a $300^{\circ} \mathrm{C}$.

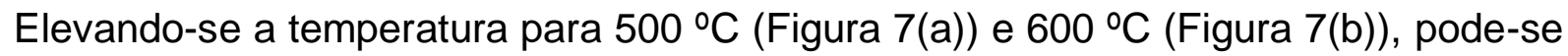
observar uma intensificação da cor avermelhada (oxidação do ferro) e também o aparecimento de um número maior de poros. 

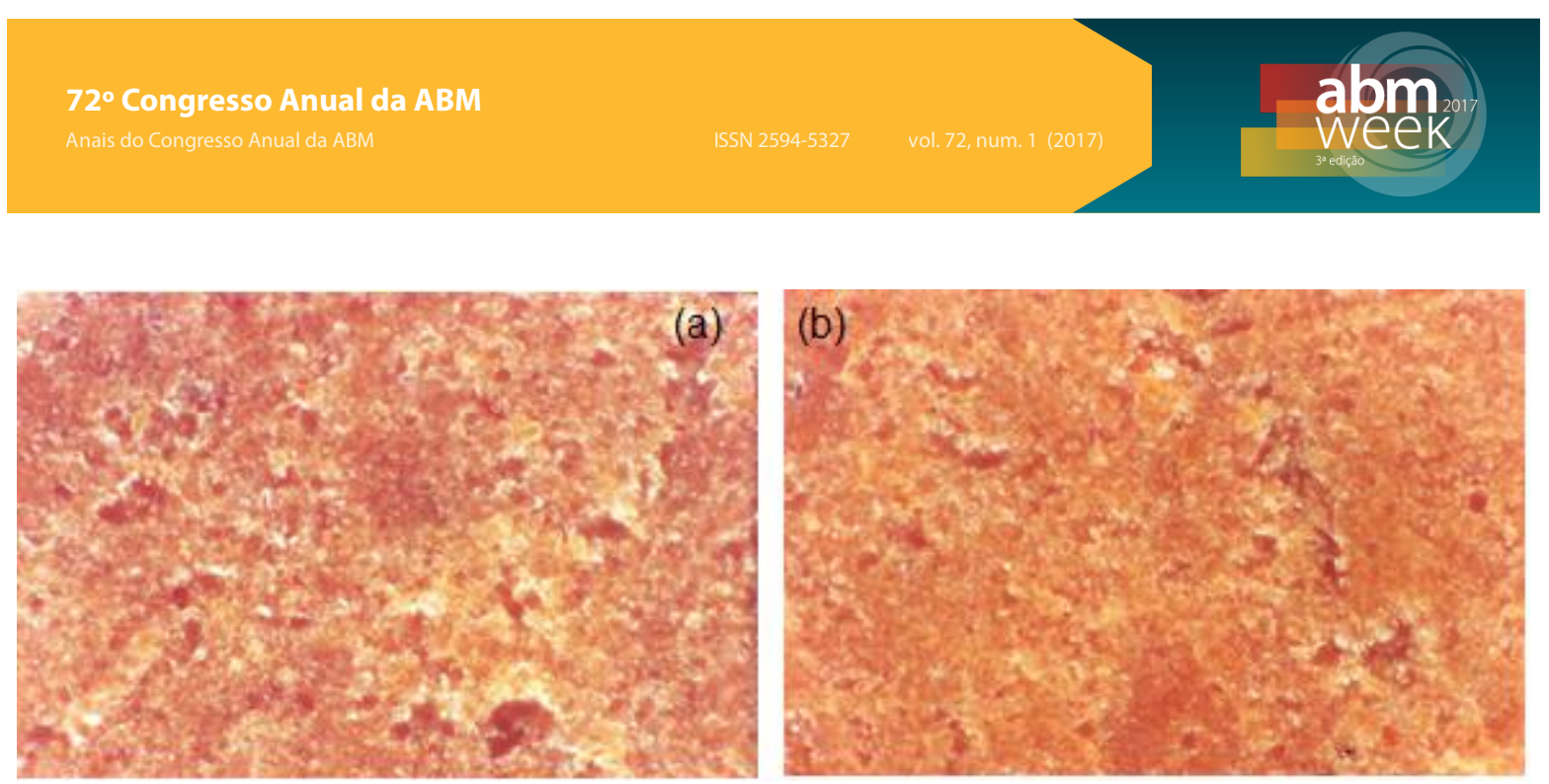

Figura 7. Fração argila queimada a (a) $500 \stackrel{\circ}{ } \mathrm{C}$ e (b) $600 \stackrel{\circ}{\circ}$.

Nas temperaturas de $900{ }^{\circ} \mathrm{C}$ (Figura 8(a)) e $1000{ }^{\circ} \mathrm{C}$ (Figura 8(b)), verificou-se um aumento gradativo no tamanho dos grãos, bem como um aumento na coesão entre eles. A cor tornou-se um pouco amarelada.
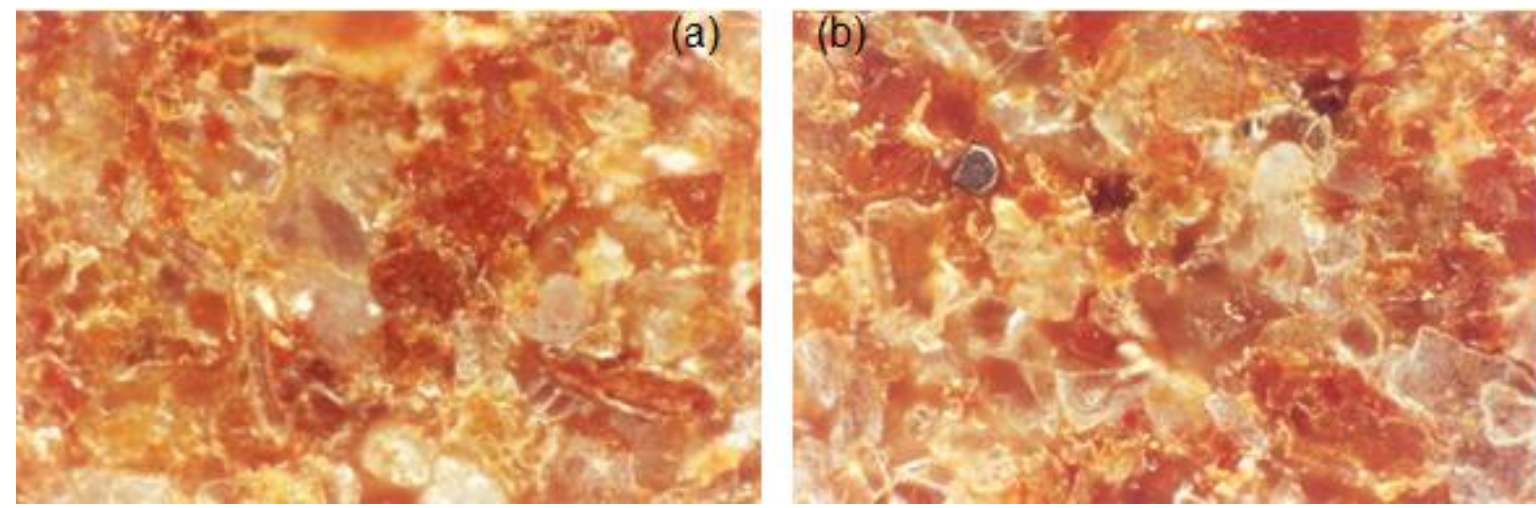

Figura 8. Fração argila queimada a (a) $900{ }^{\circ} \mathrm{C}$ e (b) $1000^{\circ} \mathrm{C}$.

De acordo com a Figura 9(a) que a fração silte apresenta, antes da queima, um pequeno número de poros. Na Figura 9(b), nota-se que a fração silte tratada a 300 ${ }^{\circ} \mathrm{C}$ apresenta cor tendente a se avermelhar e há um aumento no tamanho dos grãos.
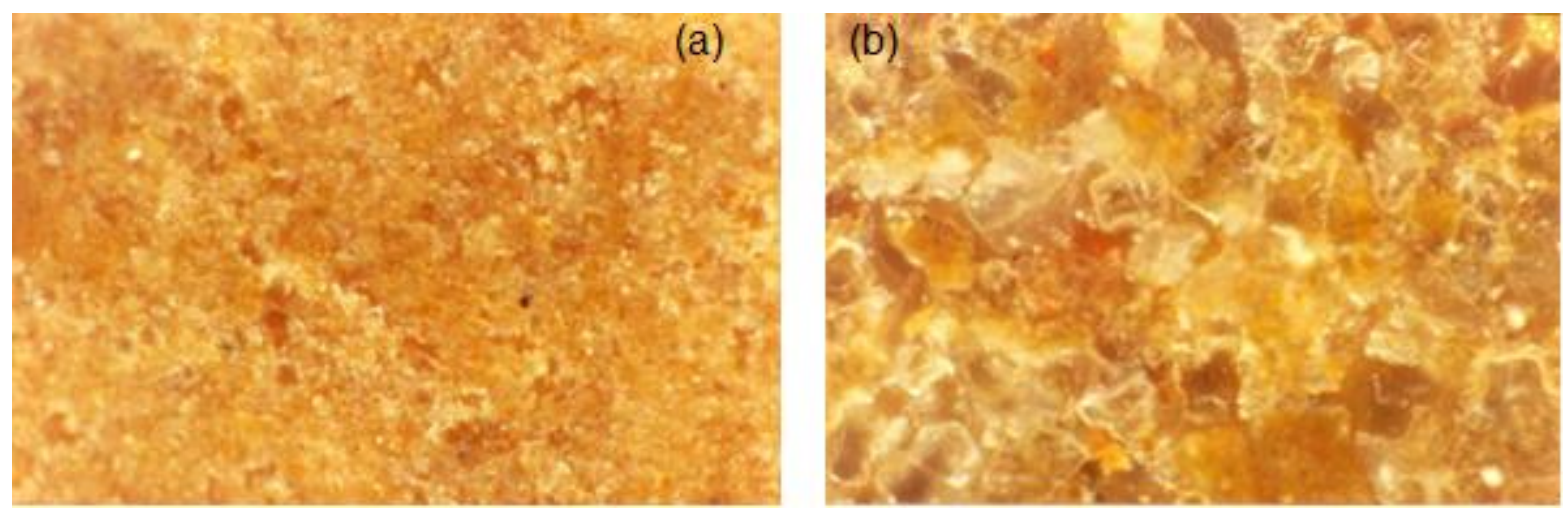

Figura 9. Fração silte (a) crua e (b) queimada a $300^{\circ} \mathrm{C}$.

Elevando-se a temperatura da queima para $500 \stackrel{\circ}{\circ}$ (Figura 10(a)), verifica-se uma grande aproximação entre os grãos e uma intensificação da cor avermelhada. $\mathrm{Na}$ temperatura de $600{ }^{\circ} \mathrm{C}$, observa-se que houve um aumento no número de poros, a alteração na coloração para um tom mais amarelado, conforme a Figura 10(b). 

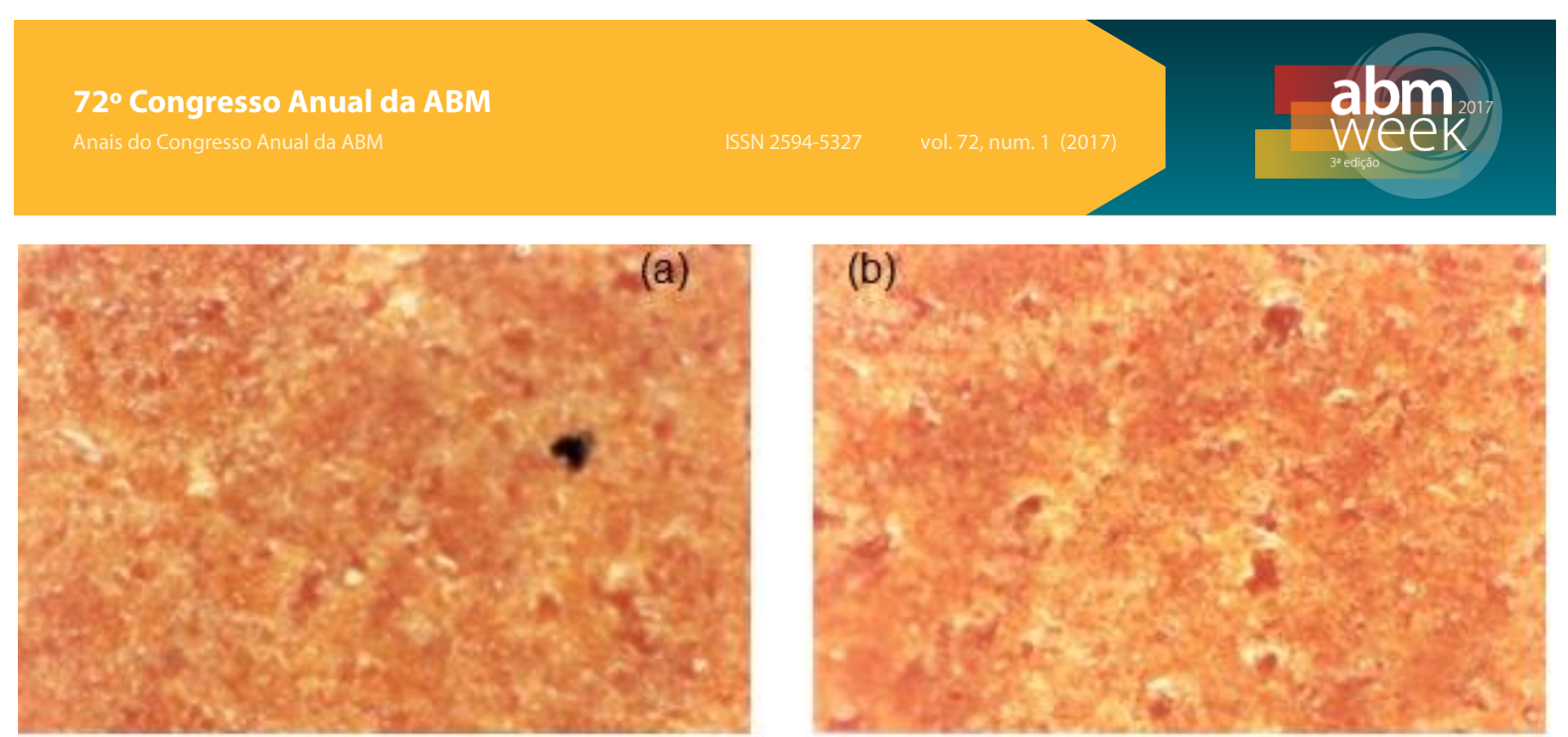

Figura 10. Fração silte queimada a (a) $500{ }^{\circ} \mathrm{C}$ e (b) $600{ }^{\circ} \mathrm{C}$.

Na temperatura de $900{ }^{\circ} \mathrm{C}$, houve um crescimento dos grãos, além de fusão destes para formar a massa cerâmica, conforme a Figura 11(a). Na Figura 11(b), com a queima a $1000 \stackrel{\circ}{\circ}$, nota-se intensificação da cor avermelhada e uma maior coesão dos grãos.
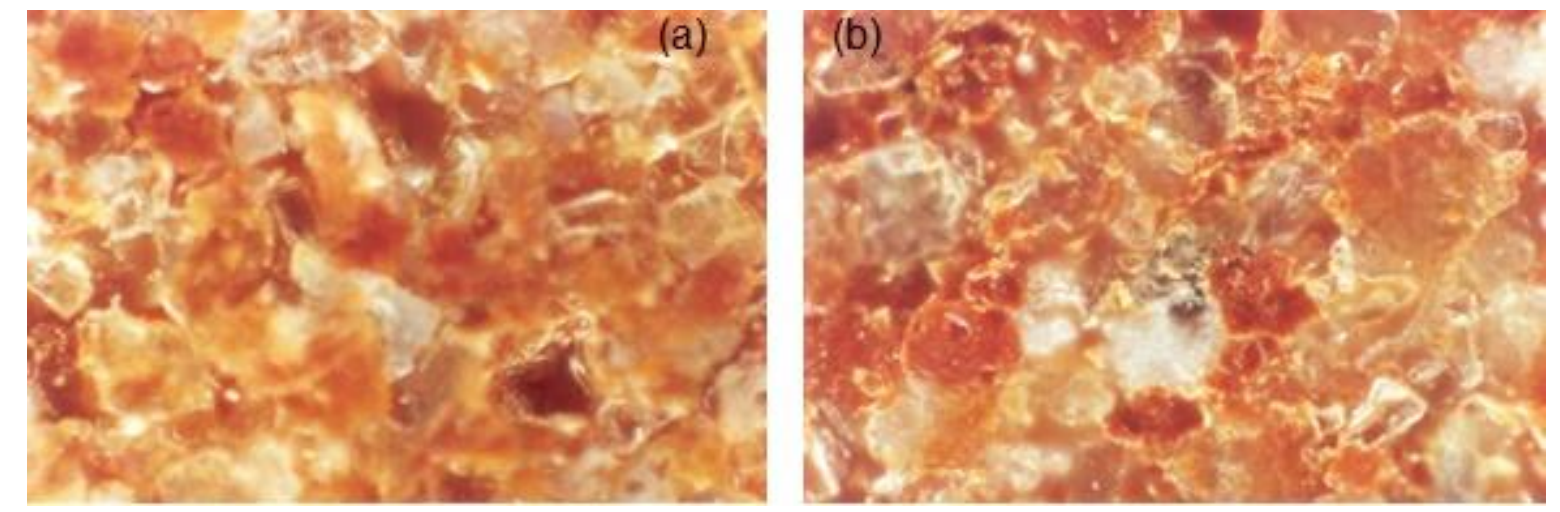

Figura 11. Fração silte queimada a (a) $900 \stackrel{\circ}{\mathrm{C}}$ e (b) $1000^{\circ} \mathrm{C}$.

\section{CONCLUSÕES}

A partir dos dados obtidos anteriormente, observa-se que o solo argiloso estudado apresenta grande teor da fração argila, definindo-o como sendo de granulometria fina. De acordo com as Difrações de Raios- $X$ as amostras apresentam os seguintes minerais em grande quantidade: caulinita e ilita e em menores proporções, os minerais: quartzo, goetita e gibsita.

Neste trabalho, de caráter inicial, foi possível separar fisicamente as frações constituintes do solo (areia, silte e argila) e identificar a sua constituição mineralógica. Entretanto, os minerais não foram separados entre si e a caracterização destas frações granulométricas foi realizada por meio de ATD, DRX e ATG, sendo a sua morfologia rastreada por microscopia óptica. Os resultados de identificação mineralógica e as transformações são condizentes com as mineralogias estudadas rotineiramente. Já a morfologia das misturas rastreadas na faixa de temperatura de 300 a $1000^{\circ} \mathrm{C}$, mostram um interessante comportamento físico, que provavelmente é o responsável pelas transformações das propriedades cerâmicas. No entanto, apesar da análise morfológica mostrar estas alterações, ainda não foi possível identificar com precisão os minerais pelas colorações, trabalho este, que com grande facilidade é realizado por pessoas treinadas em lâminas microscópicas de rochas e minerais in natura. Isso mostra a importância da 
continuidade deste trabalho, visto que, através de lâminas microscópicas em conjunto com as descritas análises, será possível prever a contribuição dos minerais em propriedades distintas.

\section{REFERÊNCIAS}

1 Souza Santos P. Ciência e Tecnologia de Argilas. São Paulo: Editora Edgard Blücher LTDA; 1989.

2 Peco G. Análise Dilatométrica de Argilo-Minerais. Cerâmica. 1970;16(24):320-336.

3 Maia LJQ, Martins TA, Gesick ALD, Salvetti AR. Caracterização de Argilas da Região de Bagé para Cerâmica Vermelha. Anais do Congresso Brasileiro de Cerâmica. $2001 ; 45$.

4 Ferrari KR, Filho PMF, Machado LA, Paschoal JOA. Análise Microestrutural de Cerâmicas tipo BIMEVOX. Anais do Congresso Brasileiro de Cerâmica. 2000;44:44801-448010.

$5 \quad$ ABNT NBR 7181. Determinação da Análise Granulométrica de Solos. 1984.

6 Gaspar LA, Souza MHO, Christofoletti SR, Moreno MMT. Caracterização Mineralógica e Química de Cerâmicas das Argilas da Jazida Sartori (SP). Anais do Congresso Brasileiro de Cerâmica. 2000;44 